\title{
COMPARATIVE AND FUNCTIONAL ASPECTS OF THE ISOPRENE PATHWAY IN FUNGI
}

\author{
JOHN D. BU'LOCK \\ Microbial Chemistry Laboratory. Department of Chemistry. \\ The University. Manchester M13 9PL. England
}

\begin{abstract}
The main pathways of isoprenoid biosynthesis in fungi are reviewed, with particular emphasis on the sterol and carotene pathways and on the comparative aspects of particular features. Isoprenoid biosynthesis in Mucorales is considered in more detail. In these fungi the mechanisms of isoprenoid metabolism, and an understanding of their regulation, are crucial for a biochemical interpretation of their system of sexual reproduction. More generally, mechanistic and regulatory studies are as suitable as structural data for comparative exercises in biochemical taxonomy, but the present range of available information is in many respects too limited.
\end{abstract}

\section{INTRODUCTION}

Our present understanding of secondary metabolism in microorganisms is at the same time too good, and too poor, to encourage a comparative survey. Too good because of the enormous number of special metabolites now known, and the considerable variety which still exists within the various 'simplifying' categories we have developed. Too poor, because this knowledge serves mainly to reveal the extent of our ignorance, particularly when it is set against the even greater variety of microorganisms. The field of fungal metabolism with which our own work has mainly been concerned is a very popular onet, but most of the species we know about are only represented by the isolation of a single metabolite; how many have been subjected to really thorough examination for all kinds of secondary metabolites? For a really intensively-studied organism like Gibberella fujikuroi it might be possible to put down a list of perhaps half a dozen polyketides and as many 'miscellaneous' products, up to thirty diterpenoids, a dozen steroids, perhaps ten fatty acids, and so on ; my estimate is that this would constitute about a quarter of the information that is potentially available-and when it was all collected, what other sets of data could we compare it with? The state of fungal taxonomy itself is not particularly encouraging, for while many of of the more fully investigated species belong to groups whose classification is - to say the least - dubious, like the Fungi Imperfecti, few of the wellcharacterized taxa have been at all thoroughly analyzed phytochemically.

+ Material so assiduously collected and analytically arranged by Turner $^{1}$ is not further documented in this article. 
In any case, at the back of many minds is the nagging suspicion that the 'secondary genome' of microorganisms is a capricious array which is not very meaningfully integrated into the genotype. My own view is that some of these doubts arise because of a failure to understand how the secondary genome is phenotypically expressed, but that even so there is a residue of anomalies which may hold some surprises for us when we begin to take into account such possibilities as interspecific virus-mediated transfers of genetic material.

On the positive side it must be acknowledged that microorganisms are particularly convenient for intact-organism studies of biosynthesis and its regulation, so that the main outlines of biosynthetic classifications of the fungal metabolites are very clear. Working with fungi it is relatively easy to arrive at the important conclusion that valid chemotaxonomy must be based upon reactions rather than upon products. Moreover the daily routine of the laboratory emphasizes the effects of environmental parameters on genotype expression and we see that the 'senses' of a microorganism are almost exclusively chemical ; this is a point of fundamental biological importance, for it means that the species-specific metabolites are at least as critically evaluated by other microorganisms as they are by phytochemists. Clearly, the study of microbial products has several different aspects; we might list them as: (a) structural and biosynthetic; (b) regulatory (phenotypic); (c) functional-within and between organisms; and (d) genotypic. Each of these aspects constitutes a valid framework for comparative studies.

To illustrate this argument, I have chosen the topic of isoprenoid biosynthesis in fungi, with special reference to its importance in one particular group, the Mucorales. Work on this specific problem, in one aspect or another, has occupied much of our recent attention, but the comparative dat I have used here come from many laboratories, and so far as the mechanisms of steroid biosynthesis are concerned I rely totally upon other groups. $\dagger$ My justification for choosing this example is that the regulatory and functional aspects of the pathway have some fundamental biological significance ; in its lowest terms, the combination of drugs and sex is said to guarantee wide interest!

\section{OUTLINE OF THE PROBLEMS}

The taxonomic position of the Mucorales is represented in Figure 1, which is of course based upon Ainsworth and Bisby's Dictionary of the Fungi ; we shall ignore the trichomycetes and the entomophagous fungi, because neither I nor anyone else has any chemotaxonomic information about them. The division of the class Phycomycetes between oomycetes and zygomycetes is very marked, and some authorities can see little real connection between them; both form aseptate coenocytic mycelia and that is about all they have in common. Oomycetes are mainly aquatic, have motile flagellate spores, use cellulosic polymers in their cell walls and make lysine by the plant pathway: the mucoraceous fungi reproduce asexually and sexually by

+ Data covered in the more important recent reviews ${ }^{2 \ldots 5}$ is not, in general further documented here. 


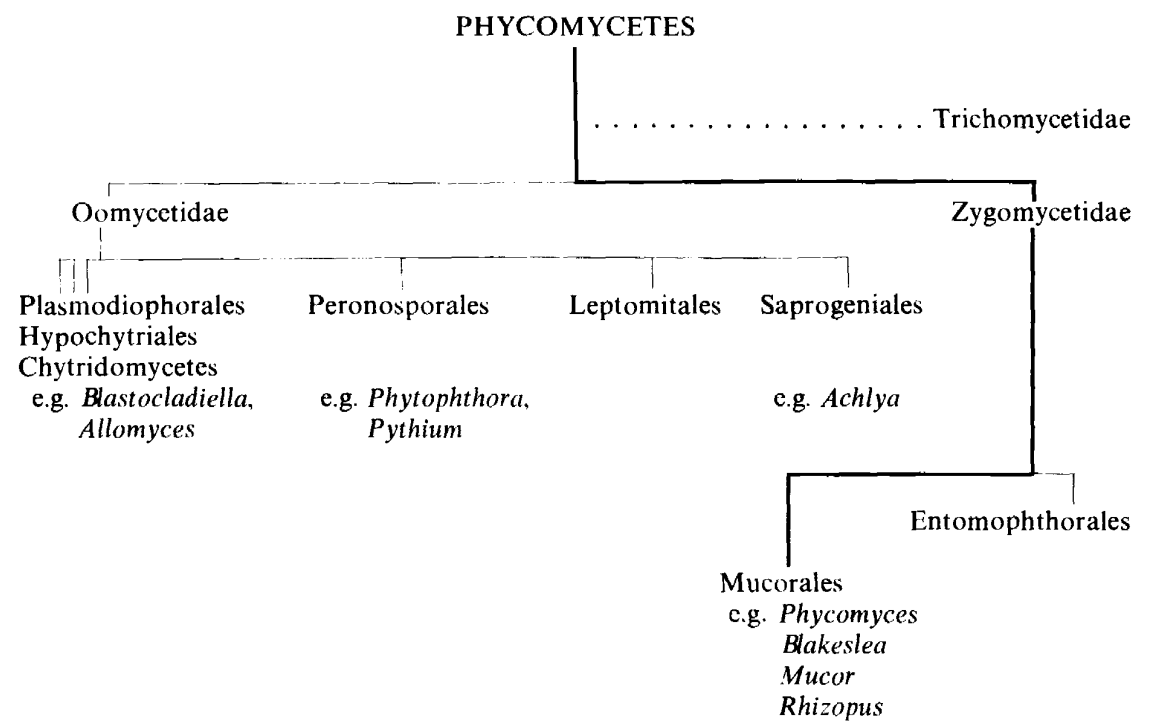

Figure 1. Taxonomic relationships of the Mucorales

specialized hyphal outgrowths, have chitin in the cell walls, and make lysine by the fungal pathway. The morphological subdivisions of the Oomycetidae are also satisfactorily correlated with nutritional requirements and appear to be phylogenetically well-based.

The Mucorales include such well-known organisns as Phycomyces blakesleeanus (admirably monographed in all aspects save the phytochemical by Delbrück and co-workers ${ }^{6}$ ) and the common bread-moulds, Mucor. Many species are heterothallic, i.e. can reproduce sexually when two appropriate strains, said to be of opposite mating type and designated plus and minus, grow into sufficient proximity. Interdiffusion of chemical signals then causes the plus-minus pair to produce hormones, the trisporic acids, which will cause both partners to begin the differentiation of specialized hyphal outgrowths, the zygophores. This occurs even if the mating types are of different species. The zygophores grow towards each other, and if they belong to the same (or two closely-related) species they respond to mutual contact by delimitation and formation of a fusion cell which develops into the zygospore. The process is represented schematically in Figure 2 and is described (similarly idealized) in most textbooks of mycology. The plus-minus distinction is said to represent two forms of a single allele, presumably in a regulatory locus or 'supergene'; the two mating types are not, in general, morphologically or functionally distinct (isogamy). The zygophores differ chemically from vegetative mycelium and from asexual conidiophores, and in their mutual attraction (zygotropism) and specific contact responses (thigmotropism).

The biosyntheticframework which underpins the sexual process, and which provides us with the connecting theme in this presentation, is outlined in Figure 3. The normal mevalonate pathway leads to the four types of iso- 
JOHN D. BULOCK
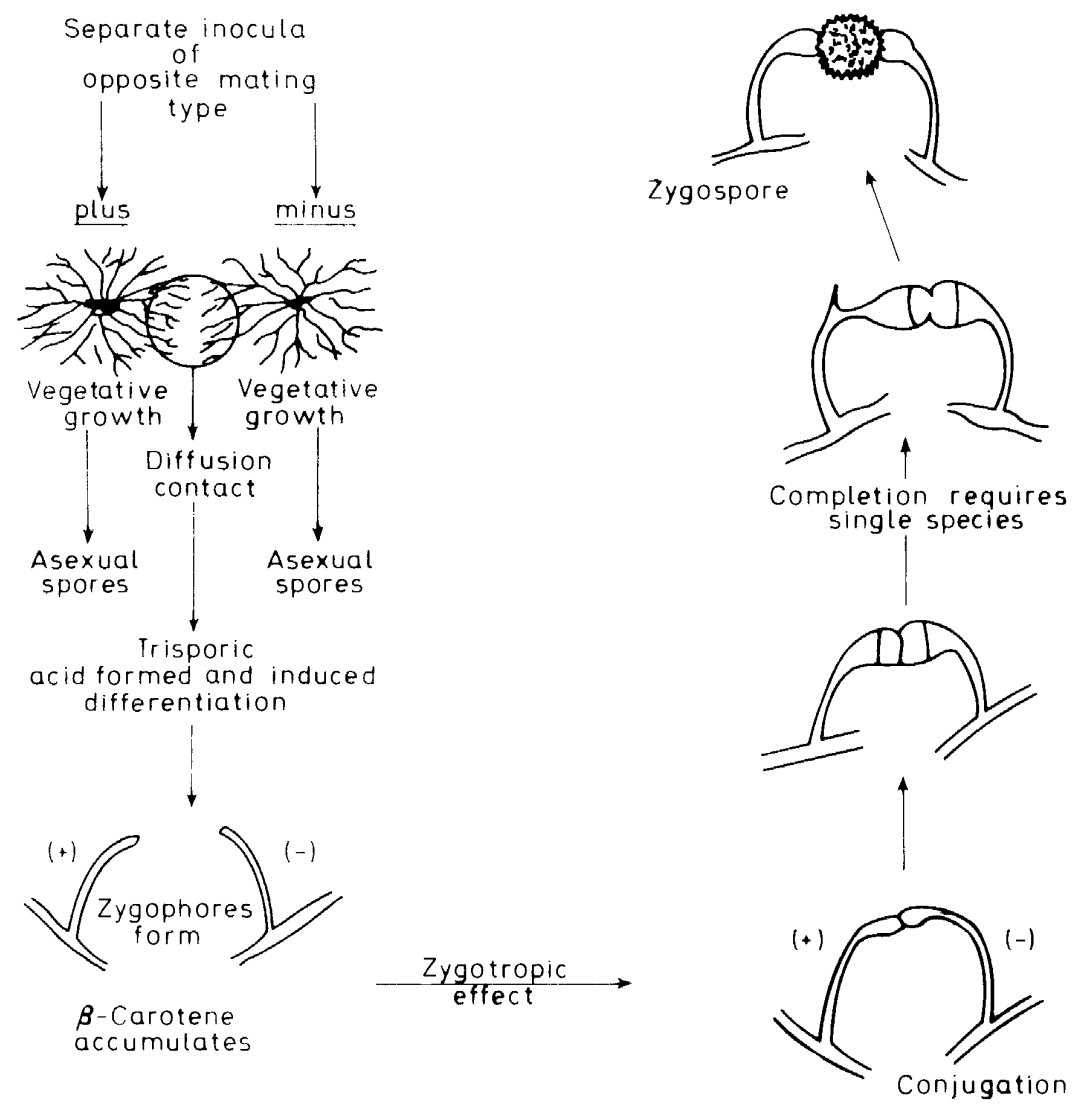

Figure 2. Heterothallic reproduction in Mucor species.

prenoids we shall discuss, namely steroids, prenols, ubiquinones, and carotenoids. From $\beta$-carotene (I), the plus-minus combination produces the trisporic acids (II) and these then act as inducers for enhanced biosynthesis in the whole isoprenoid pathway. Consequently the plus-minus system forms a control loop with positive feedback. and the direct and indirect consequences of this effect are very far-reaching (Figure 3).

Our own studies in this field have been with two particular organisms. Blakeslea trispora has been employed for most of the biosynthetic studies since it can be grown in quantity in submerged culture and shows a strong 'sexual' response in chemical terms. For bioassays and microbiological observations surface cultures of the classic heterothallic species Mucor mucedo have been used $t$.

+ My collaborators have been D. J. Austin, D. J. Winstanley, D. Drake, S. Quarrie, B. Jones and A. U. Osagic, and the particular cooperation of G. Gooday has been invaluable. 


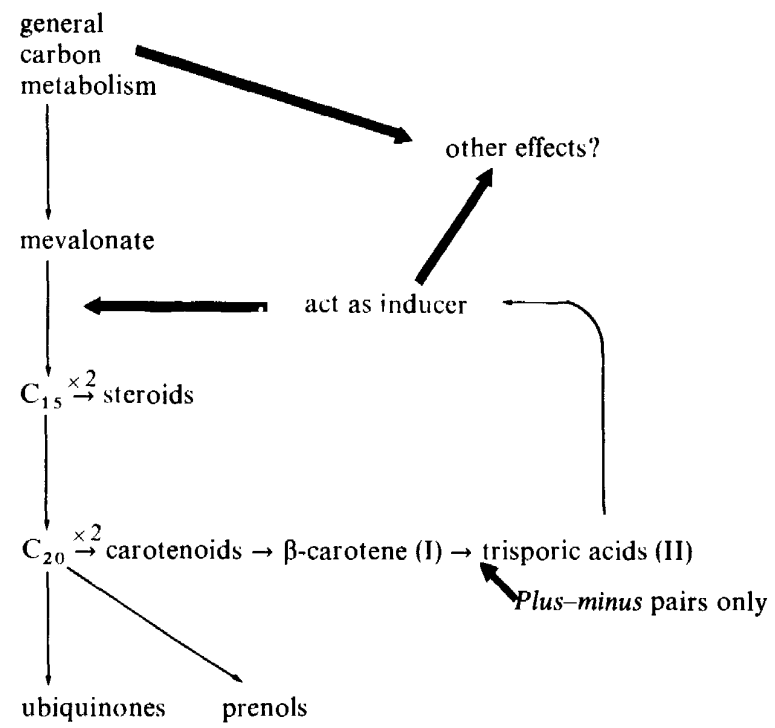

Figure 3. Biosynthetic relationships in heterothallic pairs of Mucor.

\section{STEROIDS IN FUNGI}

In B. trispora, the only major sterols are ergosterol (III) (Figure 4) and 22-dihydroergosterol; they have the same uv chromophore and we have usually measured them together and reported the result as 'ergosterol', a simplification of which others may be equally guilty. In one of the few comparative studies of fungal steroids, McCorkindale and co-workers ${ }^{7}$ gave fuller details for eight other Mucorales. The same sterols predominated, their relative proportions depending markedly on culture conditions, but in addition they found between $1 \%$ and $15 \%$ of cholesterol in Absidia glauca and Mucor hiemales; we shall consider this, and their findings for various oomycetes, subsequently.

Ergosterol (III) is the typical fungal sterol and its biosynthesis (Figure 4) is a key problem. In recent reviews ${ }^{2-5}$ attention as been focussed mainly upon the cholesterol problem in animals and the phytosterol problem in plants with ergosterol formation in yeast (Saccharomyces) being taken as more or less typical for fungi ; in fact Saccharomyces cerevisiae is no more typical of fungi than is Escherichia coli of bacteria and its only merit is similar, namely the availability of material and the volume of prior information.

In fungi, as in animals, sterols are formed by the cyclization of squalene oxide (IV) to lanosterol (V), whereas in plants the primary cyclization product is cycloartenol. The occurrence of alternative cyclizations is of some interest ; for example, the formation of pentacyclic triterpenes is characteristic of plants but they have also been found in lichens, several algae, one ascomycete, and at least two bacteria ${ }^{8-10}$. Such observations remind the phytochemist that even the major divisions between Orders are not inviolate. We might 


\section{2,3-oxidosqualene (IV)}
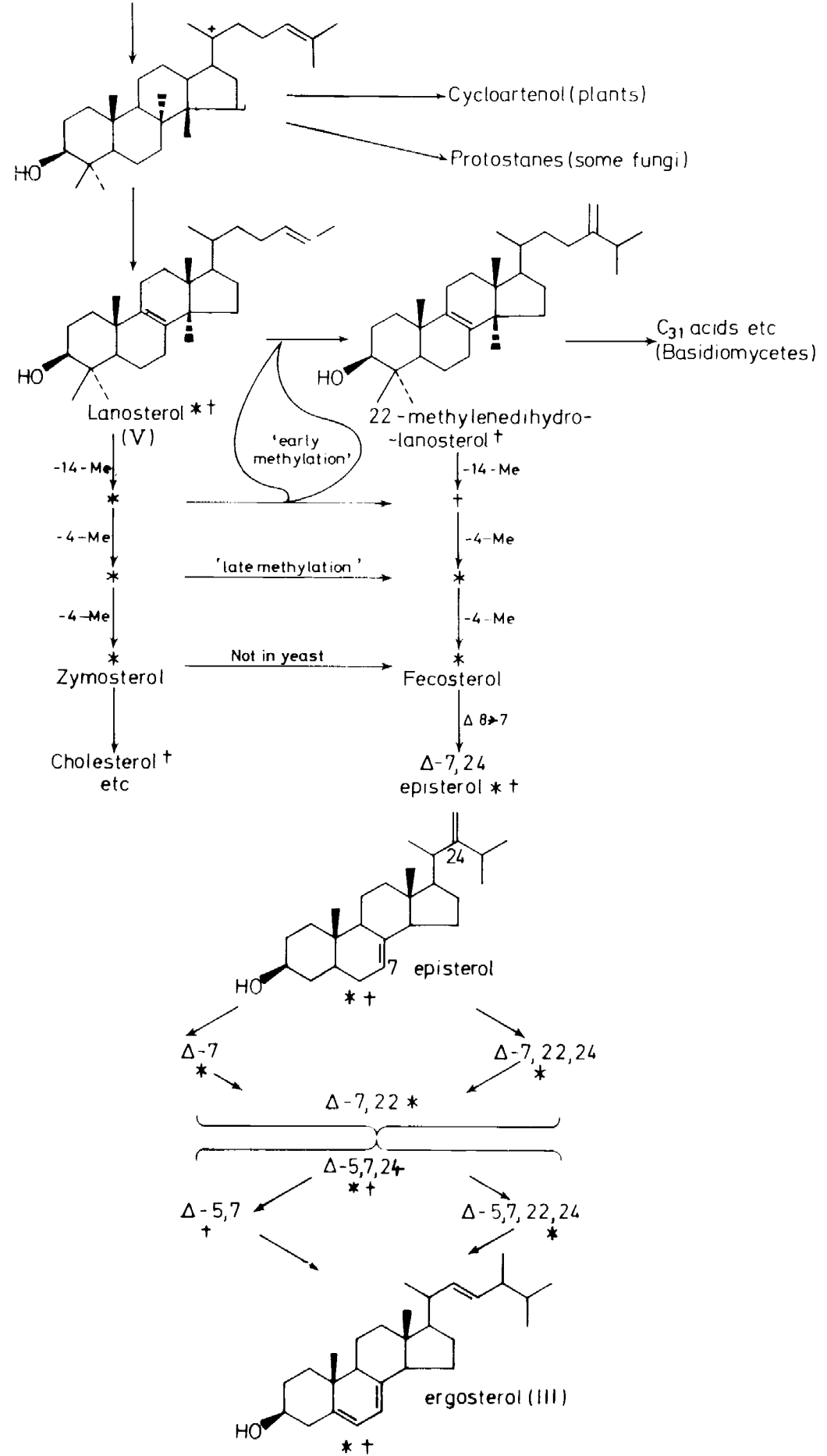

Figure 4. Biosynthesis of fungal sterols. ${ }^{*}$ in Saccharomyces; $\dagger$ in Phycomyces, etc. (See Table l). 


\section{ISOPRENE PATHWAY IN FUNGI}

correspondingly wonder whether the division between the cycloartenol and lanosterol pathways lies so precisely between plants and fungi as we now conveniently believe; algae and phytoflagellates follow the plant pathway, but lichen symbionts, some fungi which seem to produce typical phytosterols (see below), and some of the exceptional sterol-producing bacteria would perhaps repay biosynthetic study.

As a minor but interesting variant of the basic cyclization route, the protostane skeleton of several fungal products - helvolic acid, fusidic acid (VI), etc. - -is noteworthy, for just as the formation of both lanosterol and cycloartenol can be construed as alternative stabilization modes of the cation (or potential cation) formed when 2,3-oxidosqualene (IV) is cyclized, formation of the parent protosterol, 33-hydroxyprotosta-17(20),24-diene, can be viewed as yet another stabilization mode, perhaps formed when the intermediate cation (Figure 4) is generated in a slightly different conformation ${ }^{11}$. This implies that the organisms concerned form two slightly different oxidosqualene cyclases, for protosterols are formed simultaneously with the normal production of lanosterol $(\mathrm{V})^{12}$. All but one of these protosterol-producing fungi belong to the Eurotiaceae, but this is a large and perhaps not very meaningful taxon.

Within the Mucorales the existence of the lanosterol route is not in question, and the minor sterols of Phycomyces are of diagnostic significance for the pathway as we shall see; the isolations are summarized in Table 1 below. The conversion of lanosterol into ergosterol involves three different series of reactions: (a) removal of the 14-Me and 4,4- $\mathrm{Me}_{2}$ groups, (b) sidechain methylation and unsaturation changes, and (c) unsaturation changes in the ring system.

In yeast, where both reaction studies and isolation studies ${ }^{14}$ have been intensively pursued, the situation with regard to each sequence seems to be as follows (see Figure 4). The methyl groups are apparently removed in the order (1) 14-Me as formic acid, with formation of a $\Delta^{14}$ which is then reduced $^{15}$, (2) $4 \alpha-$-Me as carbon dioxide with inversion of the $4 \beta$-Me remaining giving a $4 \alpha$-Me product, (3) the remaining $4 \alpha$ group. Thus fungal steroids are $4,4,14-\mathrm{Me}_{3}, 4,4-\mathrm{Me}_{2}$, or 4-Me derivatives, and do not include the 4,14- $\mathrm{Me}_{2}$ or 14-Me types which can be found in higher plants where the sequence is either different or more flexible. In Chlorella the methyl groups are removed in the sequence 4-4-14, intercalated with reactions in the sidechain. ${ }^{15 \mathrm{a}}$

The stereochemical course of the 4-methyl eliminations may well be fixed in the lanosterol sequence, so that even such a highly-degraded 4-methylsteroid as viridin (VII), from Gliocladium spp., apparently retains the original $4 \alpha$-methyl, but in the fusidic-helvolic series (VI) of protosterol derivatives there is quite a different mechanism, for it appears that the $4 \beta$-methyl substituent is removed without inversion-i.e. the remaining $\alpha$-substituent is the original $4 \alpha-$ methyl $^{11}$.

Side-chain methylation requires $\Delta^{24}$ unsaturation, as found in lanosterol, and gives the 24-methylene side-chain by hydride shift from C-24 to C-25. As Figure 4 shows, the subsequent reduction of $\Delta^{24(28)}$ and introduction of $\Delta^{22}$ might occur in either order since all four possible types of side-chain are found in yeast, and alternative linear sequences are not really excluded. 


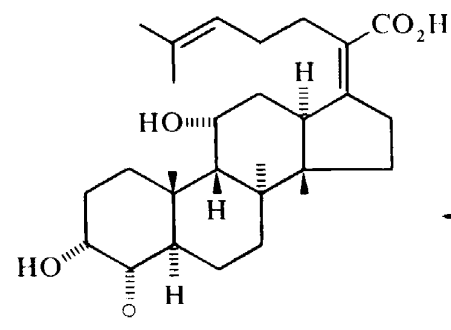

(VI) Fusidic acid

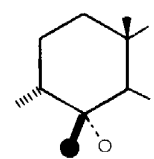

'o

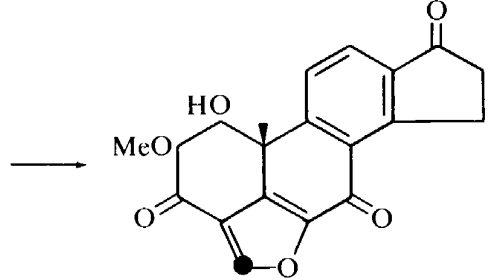

(VII) Viridin

A stereochemical point which merits further comparative study is that whereas in both Blakeslea trispora and Aspergillus fumigatus the trans- $\Delta^{22}$ system is formed by removal of two pro- $S$ hydrogens, the opposite stereochemistry obtains in two Ochromonas species (phytoflagellates).

Unsaturation changes in the ring system, apart from any connected with loss of the 14-Me, follow the sequence $\Delta^{8}$ (isomerization) $\rightarrow \Delta^{7}$; (dehydrogenation) $\rightarrow \Delta^{5.7}$, which may be followed by (reduction) $\rightarrow \Delta^{5}$. A further case of what could prove to be a systematic stereochemical difference is that whereas in yeast the isomerization step involves loss of the $7 \alpha-\mathrm{H}$, the $7 \beta-\mathrm{H}$ is lost in Ochromonas; however, the formation of $\Delta^{5}$ has the same stereochemistry in both systems.

The most uncertain aspects of this picture, and aspects which are probably of some comparative significance, are those which concern the linking of these three sequences in the biosynthetic process. Here we have yet another clear instance of the 'metabolic grid' problem which can always arise when the enzymes which catalyze a series of transformations are not absolutely substrate-specific. Indeed we should expect such a problem in this area, for the whole subject of steroid transformation by microorganisms has developed because the relevant enzymes are often specific for certain regions in the substrate molecule rather than for its whole structure. In such a problem, the demonstration that two steroids can be interconverted in a given system gives neither more nor less information about the in vivo route than the demonstration that both steroids occur together in a given organism - though enzymologists sometimes seem reluctant to concede this point. An awful warning is the facility with which plants which use the cycloartenol pathway successfully deceived experimenters by their transforming ability when supplied with lanosterol! The factors which really control reaction sequences in such systems are just beginning to be analyzed ${ }^{4,5.16}$ and experiments of the necessary refinement are beginning to be carried out; perhaps when we know more about the functioning of sterol carrier proteins ${ }^{17}$ and watersolubilizing sterol carriers ${ }^{4}$, both of which could effect some selectivity by 'isolation' of one enzyme sequence from another, the picture may be clarified. Meanwhile we must mainly rely on a judicious balancing of the available biochemical and phytochemical data.

Thus in considering the conversion of lanosterol (V) into ergosterol (III) in yeast (Figure 4) the absence of 24-methylene-lanost-8-en-3 $\beta$-ol from the very thorough isolation procedures to which this organism has been sub- 
jected $^{15}$ is at least as relevant as the demonstration that yeast will convert this compound, supplied exogenously, into ergosterol. Balancing both kinds of evidence it would appear that in yeast : (a) side-chain methylation occurs at the later stages of the demethylation sequence, perhaps mainly at the $4 \alpha$-methylzymosterol stage since zymosterol itself cannot be methylated; (b) the $\Delta^{8} \rightarrow \Delta^{7} \rightarrow \Delta^{5,7}$ sequence occurs after the demethylation sequence; (c) changes in side-chain unsaturation form a grid with the $\Delta^{7} \rightarrow \Delta^{5,7}$ step.

Thus flexibly defined, a sequence for yeast can be traced out between the starred points $\left({ }^{*}\right)$ of Figure 4 . We have already noted some ways in which parts of this sequence differ from corresponding plant and animal processes; there are also major differences in overall direction since the animal systems are directed towards (and beyond) cholesterol and the cycloartenol-based plant systems lead to a rather wide range of phytosterols, mainly $\Delta^{5}$ and with 24-ethyl and -ethylidene groups (of varied stereochemistry and detailed origin $^{3}$ ). However, the yeast system cannot even be taken as fully representative of the fungi. The presence of both 24-methylene-lanost- 8 -en-3 $\beta$-ol and its 14-nor-derivative in Phycomyces ( $\dagger$ in Figure 4) and also Agaricus campestris, and of eburicol, which is 24-methylene-lanost-8-en-3 $\alpha$-ol, in Fomes officinalis shows that, as in plants, the side-chain alkylation step can occur at the $\mathrm{C}_{30}$ (and perhaps also $\mathrm{C}_{29}$ ) level. In Basidiomycetes (of the Polyporaceae and Agaricales) this 'early' methylation is an important route since it leads to the $\mathrm{C}_{31}$ triterpene acids which (with their lanostane analogues) are major metabolites of many species ${ }^{1}$. A different variation must be assumed in Aspergillus fumigatus where the $\Delta^{8} \rightarrow \Delta^{7}$ isomerisation can occur at the $4 \alpha$-methyl stage (or earlier) with normal side-chain alkylation, to give 24-methylenelophenol.

From the major sterols listed in Table 1 (and marked + in Figure 4) it also appears that Mucorales are perhaps 'more typical fungi', as regards their route to ergosterol, than is yeast - if commercial Saccharomyces cerevisiae is indeed a typical yeast. On the other hand, the cholesterol of Mucor hiemalis and Absidia glauca (Table 1) is far less 'typical', though it is also reported from one Penicillium. However, it is in other sections of the Phycomycetes, the aquatic Oomycetidae, that the major phytochemical anomalies occur. In three Peronosporales (see Figure 1) McCorkindale's group found no sterol at all, and indeed it is now well known that these fungi cannot synthesize

Table 1. Sterols from mucorales

\begin{tabular}{|c|c|}
\hline Sterol & Genera in which found \\
\hline $\left.\begin{array}{l}\text { Major } \\
\quad \text { Ergosterol (III) } \\
\text { 22-Dihydroergosterol } \\
\text { Cholesterol }\end{array}\right\}$ & $\left\{\begin{array}{c}\text { From Mucor, Rhizopus, Phycomyces, } \\
\text { Absidia and Blakeslea }\end{array}\right.$ \\
\hline 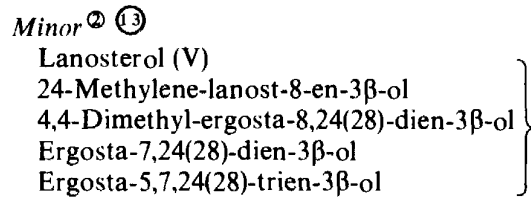 & from Phycomyces \\
\hline
\end{tabular}


JOHN D, BU'LOCK<smiles>[R]=CCC(C)CC(C)C</smiles>

Sterol

(a) Cholesterol<smiles>CC(C)=CCCC(C)C</smiles>

(b) Desmosterol<smiles>[R]C1CCC2[C]1CCC1C2CC=C2CC(O)CC[C@@]21C</smiles><smiles>C=C(CCC(C)C)C(C)C</smiles><smiles>CC=C(CCC(C)C)C(C)C</smiles>

(d) Fucosterol<smiles>CCC(C=CC(C)C)C(C)C</smiles>

(e) Stigmasterol (also stigmast-7-enol and -7,24-dienol)

(VIII) Fungal phytosterols<smiles>CC(C)C1=CC(=O)OC1C(O)[C@@H](C)C1CCC2C3C(=O)C=C4C[C@@H](O)CC[C@]4(C)C3CC[C@@]21C</smiles>

sterols though they require them for both sexual and asexual reproduction. Three Leptomitales and six Saprolegniales afforded cholesterol, desmosterol, 24-methylenecholesterol, and fucosterol (VIII a-e). These are so unlike the normal sterols of fungi that we can most conveniently designate them as 'fungal physosterols', and we may speculate whether they are derived from lanosterol at all. Taxonomically their occurrence certainly accords with the major subdivision of the Phycomycetes already discussed. Moreover in at least one of the Saprolegniales, Achlya, sterols of this series have a particularly important role since the modified 24 -ethyl steroid, antheridiol ${ }^{19}$ (IX), is a key 
hormone in the sexual process ${ }^{20}$. Did the Peronosporales, finding the phytosterols they needed for reproduction abundantly available in their plant hosts, lose the ability to make them? Or did the other oomycetes acquire the ability to make phytosterols by translocating appropriate genes from host plants? The oomycetes are not in fact unique, for stigmasterol (VIIIe) has been reported in a yeast, Debaromyces hansenii ${ }^{21}$; more circumstantially the uredospore stages of flax rust and bean rust (Uromyces-Uredinales-Basidiomycetes) have afforded both stigmast-7-enol and stigmast-7-24(28)-dienol, with a recent demonstration that they are actually synthesized by the fungus in germinating uredospores ${ }^{22}$.

Unfortunately nothing is yet known concerning the detailed mechanism by which the C-24 side-chain is formed in these 'fungal phytosterols', and in view of the several variant mechanisms in the true phytosterols this question would repay investigation.

The sterol pathway therefore shows a range of variations in direction, in sequence, and in mechanistic detail, all of which seem likely to have significance in biosynthetic taxonomy.

In Figure 5 I have attempted to set out some of the phytochemical variables

\begin{tabular}{|c|c|c|c|}
\hline \multirow[b]{2}{*}{ Feature } & \multicolumn{2}{|c|}{$\begin{array}{c}\text { Biosynthesis of Sterols } \\
\text { in }\end{array}$} & \multirow[b]{2}{*}{ Animals } \\
\hline & Plants & Fungi & \\
\hline $\begin{array}{l}\text { Pentacyclic } \\
\text { triterpenes }\end{array}$ & Common & Rare & Absent \\
\hline $\begin{array}{l}\text { First formed } \\
\text { sterol }\end{array}$ & Cycloartenol & Lanosterol & Lanosterol \\
\hline End sterols & $\begin{array}{l}\text { Phytosterols } \\
\left(C_{24} \text { alkylations }\right)\end{array}$ & $\begin{array}{l}\text { Ergosterols } \\
\text { (Protostanes } \\
\quad \text { in Eurotiales) } \\
\text { Fungal phytosterols } \\
\text { Cholesterol in some } \\
\text { genera }\end{array}$ & Cholesterol \\
\hline $\begin{array}{l}\text { Order of methyl } \\
\text { group removal }\end{array}$ & Varied & $14,4 \alpha, 4 \alpha$ & $14,4 \alpha, 4 \alpha$ \\
\hline 24-Alkylation & Common & $\begin{array}{l}\text { 24-Me common } \\
\text { 24-Et rare }\end{array}$ & Absent \\
\hline Occurs & Varied & $\begin{array}{l}\text { Early (or } \\
\text { late in yeasts) }\end{array}$ & \\
\hline $\operatorname{Trans} \Delta^{22}$ & $\begin{array}{l}\text { By loss of } 2 \text { pro } R \\
\text { H (Ochromonas) }\end{array}$ & $\begin{array}{l}\text { By loss of pro } S \\
\mathrm{H}(\text { Aspergillus and } \\
\text { Blakelea })\end{array}$ & Absent \\
\hline$\Delta^{8} \rightarrow \Delta^{7}$ & $\begin{array}{l}\text { 7- } \beta \text {-H loss } \\
\text { (Ochromonas) }\end{array}$ & $\begin{array}{l}7-\alpha-\mathrm{H} \text { loss } \\
\text { (yeasts) }\end{array}$ & $7-\beta-H$ loss \\
\hline
\end{tabular}

Figure 5. Variation in sterol biosynthesis in fungi, plants and animals.

in fungal steroid synthesis, as a brief summary of the foregoing discussion, showing variations within the subkingdom and comparisons with the corresponding plant and animal systems. The analysis is entirely provisional and obviously incomplete, but it demonstrates that there are major comparative problems awaiting investigation in this field. 


\section{UBIQUINONES IN FUNGI}

As their name implies, the ubiquinones ${ }^{23}(\mathrm{X})$ are of very wide distribution in nature, having been detected in all groups so far examined except the Gram-positive bacteria and the blue-green algae and having a fundamental role in oxidative and photo-phosphorylation, always as part of highlystructured membrane-based organelles. Their biosynthesis seems to follow a standardized route and many of the structural variants reported in older literature seem to be either artefacts or further metabolites. Such substances offer relatively little scope for comparative chemistry.

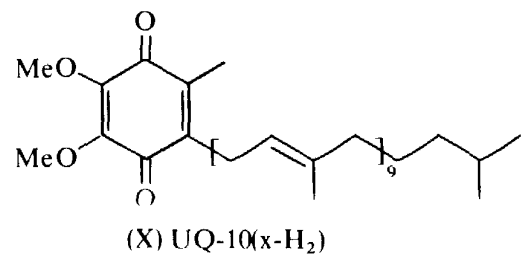

One variable aspect may be in the ultimate origin of the toluene ring. In animals and in higher plants the requisite precursor, $p$-hydrox ybenzoic acid, is formed from phenylalanine or tyrosine by the ammonia lyase- $\beta$-oxidation route, while in bacteria it arises directly from the $\mathrm{C}_{6} \mathrm{C}_{1}$ nucleus of chorismate. In fungi the $\mathrm{C}_{6} \mathrm{C}_{3}$ route operates, but the $\mathrm{C}_{6} \mathrm{C}_{1}$ route is not excluded, and this situation is not without parallel in other fungal products ${ }^{24}$. However this is an aspect which cannot be adequately pursued here.

The ubiquinone side-chain is all-trans, both stereochemically and biosynthetically. The only significant variables in the ubiquinones are, in fact, the chain-length and the occasional presence of a reduced, sometimes and perhaps always terminal. isoprene unit $(\mathrm{X})$. The general range of homologues (from UQ-1 to UQ-12) has been reviewed ${ }^{23}$ and we shall consider only the situation in fungi ; most of the data come from the work of Law et al. ${ }^{25}$

Baker's yeast, Saccharomyces cerevisiae, is anomalous in its content of short-chain ubiquinones, with UQ-6 as the predominant species; it is not known whether this situation occurs in all races of this species, however. Ascomycetes in the genera Alterneria, Aspergillus, Penicillium, and Rhodotorula (all Moniliales) and Claviceps and Gibberella (Hypocreales) all contained either UQ-9, UQ-10, UQ-9 $\left(\mathrm{H}_{2}\right)$ or UQ-10( $\left.\mathrm{H}_{2}\right)$ as the predominant ubiquinone, while a Basidiomycete, Agaricus, and a Phycomycete (zygomycete), Phycomyces, also contained mainly UQ-9. Our own investigation of Blakeslea trispora ${ }^{26}$ gave a slightly different picture in that both UQ-9 and UQ- $9\left(\mathbf{H}_{2}\right)$ were present in approximately equal amounts. However, this may not be really unusual, for in the mass spectra which offer the main diagnostic aid, the molecular ions of the side-chain dihydro species are easily confused not only with the +2 isotope peak but also with the hydroquinone peak which is sometimes generated from quinones. The problem is resolved if spectra of the hydroquinone mixture are also recorded.

On present information, therefore, we cannot foresee whether there are worthwhile comparative problems in the fungal ubiquinones, but it seems unlikely. Apart from the occurrence of ubiquinones with the dihydroprenyl 
side-chain which appear peculiar to fungi, the pattern is not very different in other organisms. A presumably analogous $A r$-prenylation reaction which might at least be noted is presumably involved in the formation of a small series of fungal metabolites (grifolin etc. ${ }^{1}$, helveticone ${ }^{27}$ and bovinone ${ }^{28}$, mycophenolic acid ${ }^{29}$ ) which occur rather sporadically in Basidiomycetes and Imperfecti; if the series becomes more extensive it may prove to have some chemotaxonomic interest, but the relationship to ubiquinones is marginal.

\section{FUNGAL PRENOLS}

The long-chain polyisoprenoid alcohols or prenols ${ }^{30}$ form a group which in some ways resembles the ubiquinone series: they are very widely distributed, though often in such small amounts that reports of their non-occurrence are dubious, and they have a fundamental biochemical role in the biosynthesis of a variety of cell-wall polymers and other extra-membrane materials, first established in relation to various bacterial polymers but now known in fungal ${ }^{31}$ and animal systems too. Information as to the types of prenol in various organisms is limited but it seems the series may have more comparative interest than the ubiquinones (Table 2).

With the exception of solanesol and the other all-trans prenols that are precursors of the side-chains of ubiquinones (and similar prenylated quinones in green plants), the prenols are formed from an all-trans-precursor, either farnesyl or geranylgeranyl, by repeated cis-prenylations (the 'anomalous' stereochemistry which also occurs in natural rubbers). Prenols can therefore differ in the chain-length of the all-trans-precursor, $\mathrm{C}_{15}$ or $\mathrm{C}_{20}$, and in the total chain length - most sources afford mixtures. The isoprene units are conveniently designated, from the hydroxyl terminal, as $\alpha, \ldots, \psi, \omega$. Prenols may differ by having a reduced $\alpha$-unit (it being ambiguous to term these 'dolichols' so long as this special term also carries implications about the number of biogenetically-trans units), by having a reduced $\omega$-unit, and by having the $\psi$-unit either reduced or methylated; the last-named modification

Table 2. Natural prenols

\begin{tabular}{lccccc}
\hline \multicolumn{1}{c}{ Source and type } & $\begin{array}{c}\text { No. of bio- } \\
\text { synthetic trans } \\
C_{5} \text { units }\end{array}$ & $\begin{array}{c}\text { Predominant } \\
\text { no. of } \mathrm{C}_{5} \\
\text { units }\end{array}$ & Range & $\begin{array}{c}\text { Hydro- } \\
\text { genated } \\
\text { residues }\end{array}$ & $\begin{array}{c}\text { Other } \\
\text { modifica- } \\
\text { tions }\end{array}$ \\
\hline $\begin{array}{l}\text { Solanesols* } \\
\text { Mammalian dolichols }\end{array}$ & All & 9,10 & $2-12$ & none & none \\
Bactoprenols & 3 & 18,19 & $16-22$ & $\alpha$ & none \\
Betulaprenols & 3 & 11 & - & none & none \\
Castaprenols $\dagger$ & 3 & 7,8 & $6-9$ & none & none \\
Plant 'dolichols' & 4 & 11,12 & $9-13$ & none & none \\
Chlorella 'dolichol' & $?$ & $?$ & $?$ & $\alpha$ & $?$ \\
Yeast 'dolichol' & $?$ & $?$ & $?$ & $\alpha$ & $?$ \\
Aspergillus fumigatu: & $3 ?$ & $?$ & $13-18$ & $\alpha$ & none \\
Aspergillus niger & 4 & $20-22$ & $18-24$ & $\alpha \psi \omega$ & none \\
Blakeslea trispora & 4 & 20,21 & 18,24 & $\alpha \psi$ & $\omega$ is $+\left(\mathbf{H}, \mathrm{CH}_{2}\right)$ \\
\hline
\end{tabular}

* Including precursors of side-chains of ubiquinones, etc.

+ Widely distributed especially in chloroplasts 
gives a $\mathrm{C}\left(: \mathrm{CH}_{2}\right) \cdot \mathrm{CH}_{2} \mathrm{CHMe}_{2}$ unit by a step superficially analogous to 24-methylation in steroids. Table 2 summarizes these variations as they have been reported for prenols from a variety of sources ${ }^{30-34}$.

The low quantity in which these prenols usually occur, and their somewhat intractable nature, have perhaps discouraged the phytochemical approach but there seems to be scope for some systematic investigation here. Even in the limited range of present data there are anomalies, like the single report of an $\alpha-\mathrm{H}_{2}$ bacterial prenol and the report that the $\alpha-\mathrm{H}_{2}$-prenol of Saccharomyces has only three (two internal) trans units. If further investigation substantiates these reports then considerable work needs to be done within the main classes of organism; if the reports are eliminated, a basic pattern seems to be emerging in which further studies of the fungal prenols are particularly desirable. The sequential relationship between the two distinct stages of chain-assembly on the one hand and the hydrogenation steps and other modifying reactions on the other would also be interesting to determine-obviously the $\alpha-\mathrm{H}_{2}$ prenols can only be formed after the chain has been built up but the modifications in the $\psi$ and $\omega$ residues found in the Aspergilli could. in principle, originate at an earlier stage.

\section{FUNGAL CAROTENOIDS}

In view of the considerable success which has followed the systematic study of carotenoids in algae and photosynthetic bacteria ${ }^{35}$, our comprehension of fungal carotenoids, at least from a chemotaxonomic viewpoint, is disappointing, particularly since fungi such as Neurospora crassa and Phycomyces blakesleeanus have played such an important role in the investigation of carotenoid biosynthesis. Part of the problem is that carotenoid pigments may often be conspicuous in the fruit-bodies of fungi growing in the field. receiving superficial attention therefore from the systematicist but remaining inaccessible in chemically useful quantity, while in vitro the production of carotenoids by vegetative mycelium is peculiarly susceptible to environmental factors such as temperature, light and nutrient balance. Yields are often low and characterization very critical, and the number of laboratories with the patience and expertise these substances require is rather limited. A proportion of the older work, particularly on xanthophylls, has to be discounted, but only reliable re-investigations can assure us what the proportion is. For example, I have assumed that there are no fungal carotenoids with $x$-type rings, but I may well be wrong.

The basic biosynthetic pathway is of course the sequence of dehydrogenation (d) and $\beta$-cyclization steps ( $\beta$ ) starting from phytoene (XI, Figure 6 ), in the elucidation of which the carotene-producing fungi played a major role. It is uncertain how generally some of the newer refinements to this sequence apply. For example, in at least some systems the initial synthesis of phytoene gives cis-phytoene and the dehydrogenation sequence can proceed asymmetrically (through an isomer of the structure usually written for $\zeta$-carotene), but we do not know whether these features are invariable ${ }^{36-39}$.

A historic difficulty is that in most intact-cell systems it proves impossible to demonstrate the conversion of phytoene, and in several it has been shown quite clearly that endogenous accumulations of phytoene (or of later 


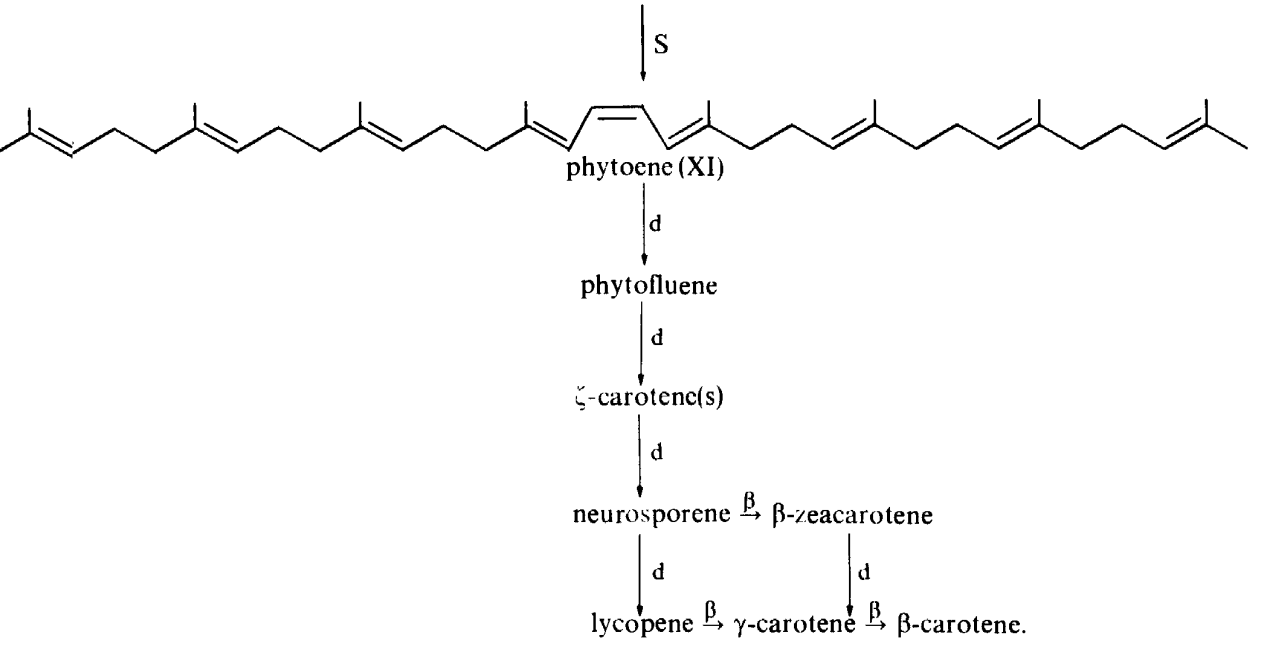

Symbols :

Figure 6. The phytocne-lycopene- $\beta$-carotene sequence.

$\mathrm{s}$-phytoene synthetase $2 \mathrm{R}-\mathrm{CH}_{2} \mathrm{O} \cdot \mathrm{PP} \rightarrow \mathrm{R} \cdot \mathrm{CH}-\mathrm{CH} \cdot \mathrm{R}$

$\mathrm{d}$-dehydrogenase<smiles>C=C(C)CCC=C(C)C</smiles><smiles>CC=CC=CC=C(C)C</smiles>

$\beta-\beta$-cyclase<smiles>CC=CC=CCC</smiles>

intermediates) whether caused naturally, or by manipulating the environmental conditions, or by adding inhibitors, are not transformed into $\beta$-carotene when the full sequence is subsequently made operational. Consequently much controversy has existed over the reality of this sequence, and in particular over the two possible routes, via $\beta$-zeacarotene and via lycopene, to $\gamma$ - and thence to $\beta$-carotene (Figure 6). Enzymological studies have now abundantly validated the overall sequence ${ }^{39}$, but a better insight into its characteristics in vivo has come from biochemical genetics. In Neurospora crassa, gene-mapping of mutants coupled with cell protein 'fingerprinting' led to the conclusion that the carotenes were synthesized in a "light-induced heteromultimeric protein complex ${ }^{\mathbf{4} 0}$. Studies by CerdàOlmedo and co-workers on Phycomyces gave a more specific picture ${ }^{41}$. In heterokaryons between different blocked mutants, with different proportions of the parent nuclei, the several enzymes responsible for phytoene synthesis, the dehydrogenations, and the $\beta$-cyclizations are synthesized independently in active or inactive forms according to the parent genotypes, and then aggregates are made up randomly, but in each assembled aggregate the enzymes are only accessible sequentially to the substrate. Such a structured multienzyme complex, operationally similar to a fatty acid synthetase, is $a$ 
Parents

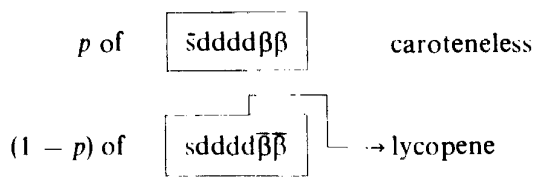

Heterokaryons

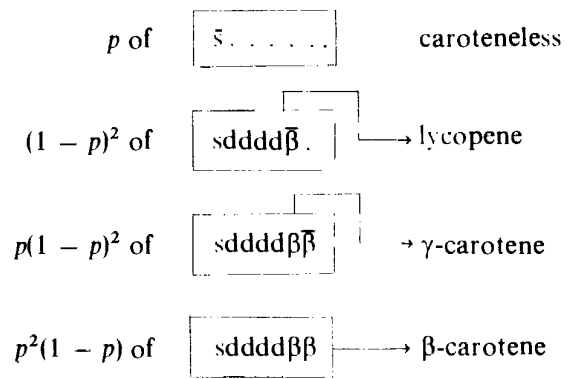

Figure 7. Heterokaryons from a caroteneless and a lycopene-producing strain (in the proportion $p:(1-p))$ and the proportions of the different synthetase complexes. Symbols as in Figure 6; also $: \bar{s}$-defective phytoene synthetase $; \bar{\beta}$-defective $\beta$-cyclase.

priori likely for such hydrophobic substrates as carotenoids, for which dissociation from a hydrophobic binding-site is energetically unfavourable. Details of the multi-enzyme complex follow from analyses of the carotenoids produced by heterokaryons containing the parent nuclei in varying proportions; the rationale for heterokaryons between a strain defective in phytoene synthesis and one lacking the $\beta$-cyclase is set out in Figure 7. It is concluded that the complex in Phycomyces contains one 'copy' of phytoene synthetase, four dehydrogenase copies, and two cyclase copies; thus, for example, a complex in which the first cyclase is defective will produce lycopene irrespective of the nature of the second cyclase unit. The authors point out how a simple topological change in the complex will give a system which makes $\beta$-zeacarotene, as observed under the influence of inhibitors like diphenylamine.

The non-conversion of potential intermediates which have been released from the complex is explained; for example ${ }^{42}$, if Neurospora is held under certain nutrient conditions (it is not clear if the experimental arrangement gave 'unlimited' or oxygen-limited growth conditions) production of the dehydrogenases is apparently suppressed and phytoene accumulates, but is not available for desaturation when the conditions are changed and more unsaturated carotenoids are formed de novo. Again, the chytrid Rhizophlyctis characteristically makes lycopene in young cultures, and $\gamma$-carotene by de novo synthesis when mature ${ }^{43}$; here the addition of cyclase to the complex apparently occurs as part of the differentiation process.

The production of $\gamma$-carotene is in fact very characteristic of chytrids (Allomyces, Blastocladiella, Rhizophlyctis) particularly in the mature or sexually-differentiated phases of their life-cycle, and it may be that in this 


\section{ISOPRENE PATHWAY IN FUNGI}

group of the aquatic Phycomycetes a five-unit carotene-synthetase is normal, with only a single cyclase copy, the addition of which is suppressed during vegetative growth. In fact, $\beta$-carotene seems to be relatively uncommon in fungi and this $\gamma$-carotene system may be more normal. For $\alpha$-carotene one or other of two cyclase units in a six-unit complex would need to have a sterically different active $\operatorname{site}^{44}$, but as already mentioned this pattern may actually be absent in fungi, and some reports of $\alpha$-carotene may refer to the methylene-isomer recently characterized ${ }^{45}$ in Caloscypha (Pseudoptectania) fulgens, a discomycete (see below).

The $\beta$-carotene pathway is of course well-developed in the Mucorales (Phycomyces, Blakeslea, Mucor, Mortierella, etc.) but anomalously-pigmented species which exist in this family have not been particularly investigated. Regulatory and functional aspects of the pathway are considered subsequently.

In several Ascomycetes (and perhaps generally) $\beta$-carotene is occasionally found but the typical carotenoids are monocyclic, and adaptation of the Cerdà-Olmedo model to this case suggests a synthetase complex with five dehydrogenase copies and only one $\beta$-cyclase, [sdddddc] to give the scheme of Figure 8. This basic pathway seems to be attested ${ }^{46-48}$ in Lycogala (a Myxomycete), and amongst Ascomycetes in Neurospora (Sphaeriales), Rhodotorula, Torulopsis, Cryptococcus, Sporobolomyces, Arthrobotrys, and some Fusarium (Moniliales), and Aleuria, Plectania, Scutellinia, and Phillipsia (Pezizales); it may be of course more widespread.

From the torulene to which this sequence leads, various xanthophylls are derived (Figure 9). Thus in Neurospora spp. and some Rhodotorula a terminal methyl group is oxidized to give torularhodin; $\beta$-cleavages then generate a variety of apocarotenoids of which the $\mathrm{C}_{35}$ acid neurosporaxanthin, is the best known. In other Rhodotorula, Cryptococcus, and the Pezizales oxidation of the terminal double bond via plectaniaxanthin may also lead to apocarotenoids of the same type $\mathrm{p}^{4-49}$.

In Basidiomycetes, some Cantherellus and Peniophora spp. (Thelephoraceae) are capable of oxidizing the $\beta$-ring at $\mathrm{C}-4$, e.g. to give canthaxanthin $\left(4,4^{\prime} \text {-dioxo- } \beta \text {-carotene }\right)^{50}$, a process which is of some interest because of its relationship to trisporic acid production in Mucorales (below). Other Basidiomycete carotenoid and xanthophyll patterns undoubtedly exist but they await elucidation. It is of some comparative interest that while the fungal carotenoids seem to bear little or no resemblance to the photosynthetic

2 geranylgeranyl-PP
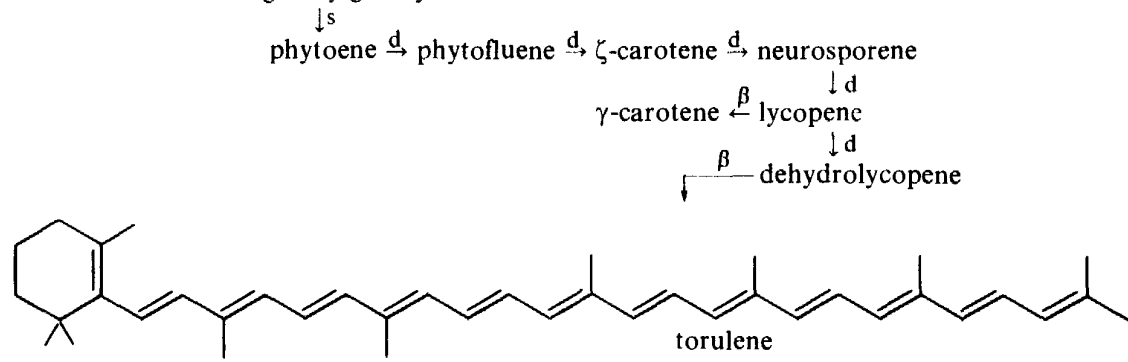

Figure 8. The monocyclic carotenoid sequence in Ascomycetes. Symbols as in Figure 6. 


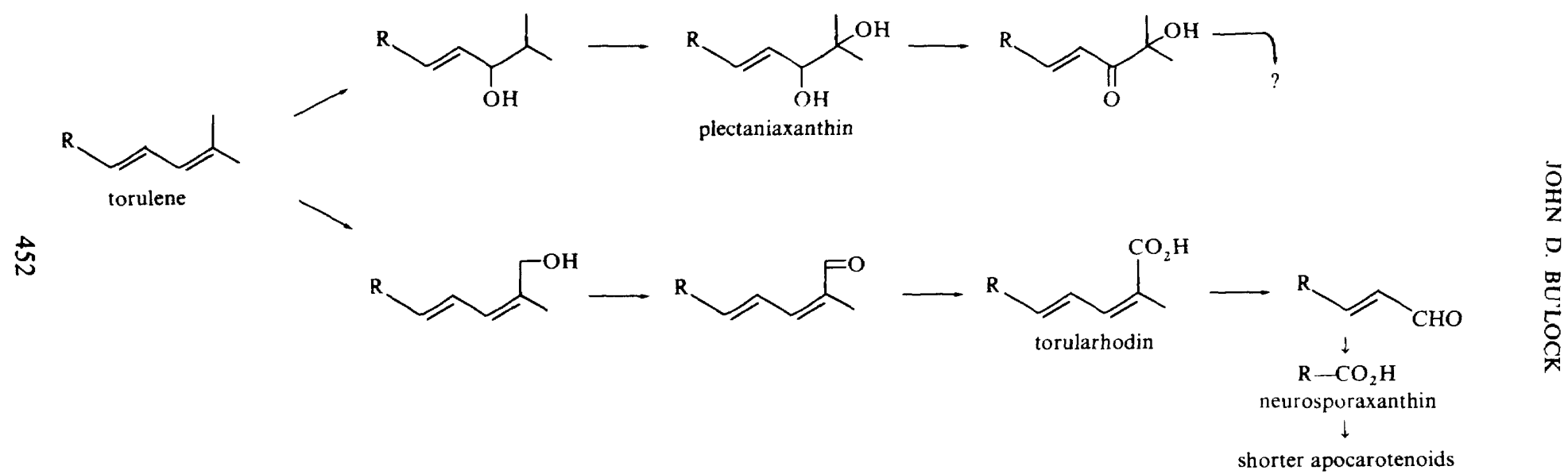

Figure 9. Biosynthesis of xanthophylls from torulene. 
Table 3. Biosynthesis of trisporic acid and trisporols in Blakeslea trispora*

\begin{tabular}{lclcc}
\hline \multicolumn{1}{c}{ Precursor fed } & Incubation & Culture & \multicolumn{2}{c}{$\%$ Incubation } \\
& period $(\mathrm{h})$ & & Trisporic acids & Trisporols \\
\hline Mevalonate-2- ${ }^{14} \mathrm{C}$ & 100 & mated & 0.9 & n.d. \\
$\beta$-Carotene-G- ${ }^{14} \mathrm{C}$ & 100 & mated & 3.5 & n.d. \\
Retinol-10- ${ }^{4} \mathrm{C}$ & 8 & mated & 18.3 & n.d. \\
$\beta-\mathrm{C}_{18}$ - Ketone-10- $^{14} \mathrm{C}$ & 16 & mated & 38.2 & n.d. \\
& 8 & plus & 9.0 & $<2$ \\
& 8 & minus & $<2$ & $25 \dagger$ \\
\hline
\end{tabular}

* See Figure 10

+ Specific activity identical with that of the administered precursor

data in Table 3 will illustrate this. In practice we have been unable to detect either of these substances in B. trispora but this is scarcely surprising in view of the very rapid conversions we have found in some tracer experiments ${ }^{53}$; traces of retinal have been found in Phycomyces ${ }^{54}$. The participation of $\beta$-carotene is reasonably well substantiated by the observed incorporations since the pool of $\beta$-carotene in the cells is so much larger than that of any subsequent intermediates; there is good genetic evidence that at least one $\beta$-cyclase step is involved since in cyclase-defective mutants of Phycomyces the whole sexual process is blocked ${ }^{55.56}$. The supposed oxidation of the $\beta$-ring at C-4 has its parallel in the formation of canthaxanthin in Basidiomycetes and algae, and the remaining steps present no particular conceptual difficulty. Though we are not wholly certain of the exact sequence of intermediate steps, the structures of some minor, inactive, cometabolites-some of which are shown in Figure 10 -.-help to confirm that suggested here. The whole sequence is oxygen-requiring, and probably oxygenase-mediated ${ }^{57}$, and the oxidation at the gem-dimethyl group is stereospecific as shown ${ }^{44}$.

In single strains the pathway is effectively 'off', though very careful work by Sutter ${ }^{56}$ has shown that some plus and minus strains of $B$. trispora do produce traces of trisporic acids---about 1/1000 of the 'mated' level in a plus strain and even less in a minus; single strains may also accumulate about $1 / 1001 / 50$ of the potential vield as trisporic acid precursors. The opening-up of the pathway in mated cultures requires de novo protein synthesis in both strains ${ }^{58}$ and once it is established both strains carry it out ${ }^{59}$. This mutual induction is somewhat difficult to understand since substrate quantities of intermediates are not exchanged ${ }^{59.60}$ and there is little direct evidence as to what 'chemical messages' are passed between the strains. We feel that it is nevertheless possible to devise a mechanism which satisfies the available data.

It is accepted that the 'sexual' difference in heterothallic Mucorales arises from two alleles of a single gene. We suppose that both plus and minus alleles produce a repressor protein for, inter alia, some of the genes coding for enzymes in the carotene-trisporate sequence. Each repressor is bound at several gene sites, with different affinities so that the low-level repressed enzyme syntheses are at different rates; such a system will be reflected in a corresponding pattern of low levels of pathway intermediates in the culture. Since the repressor proteins of plus and minus strains are slightly different, the corresponding patterns of intermediates which accumulate at low levels in 
single strains will also differ; in fact single-strain cultures do appear to differ in this manner though none of their products has so far been identified. If we now suppose that some of these intermediates also act as de-repressors for the pathway, i.e. by binding to the repressor protein and blocking its attachment to the repressible genes, the ease of de-repression (i.e. the level of derepressor required) will also differ for the plus and minus gene-products. Such a system will be self-activating in the mixed culture if the repressed level of an intermediate in one strain is higher than the de-repression threshold for the other strain. The diagrammatic representation in Figure 11 shows this principle in a simple form.

In such a mechanism the intermediates in the pathway are also the inducers for the pathway, and they are only exchanged between the two strains in inducer-quantities, not in substrate amounts. Further work will be needed to substantiate this type of mechanism, but preliminary results are promising. For example, we have recently found that added $\beta-C_{18}$-ketone

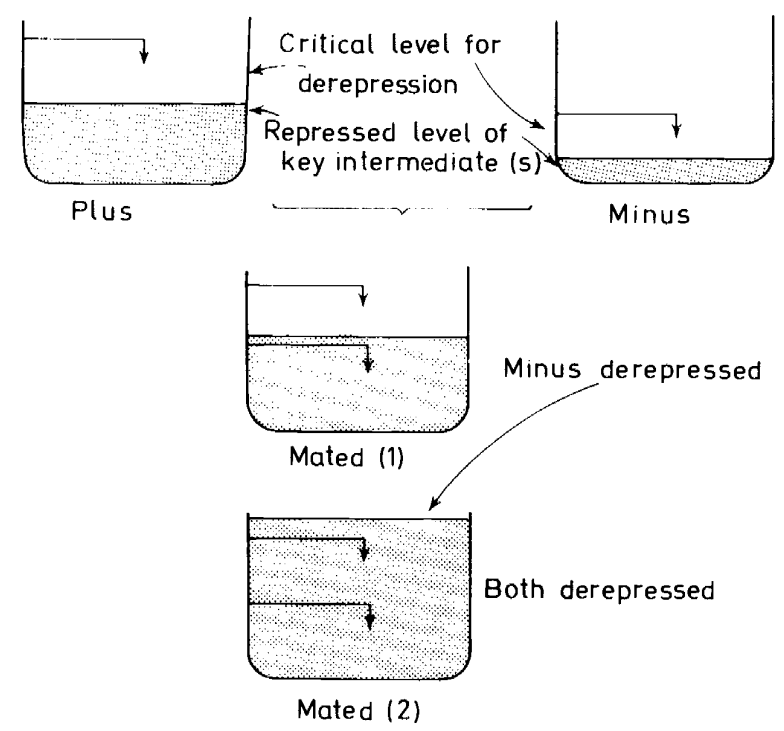

Figure 11. Diagrammatic representation of self-induction in heterothallics.

is rapidly metabolized by single strains of $B$. trispora; in the minus strain it gives significant quantities of trispor and a little trisporic acid, and in the plus strain trisporic acids with a little trisporol-C Provisional data appear in Table 3. Either the $\mathrm{C}_{18}$ stages of the trisporic acid sequence are readily induced by the $\beta-C_{18}$-ketone or they are already free from repression in the single strains; in the latter case the repressible part of the sequence lies between $\beta$-carotene and the $\beta-C_{18}$-ketone. Appropriate differences in 'un-induced' reactivity between plus and minus strains had already been substantiated, in particular in their conversion of trisporols into trisporic acids ${ }^{52}$. 


\section{Mode of action of trisporic acids}

Once formed. the trisporic acids cause mycelia of the single strains to put out the specialized hyphal branches, the zygophores, which characterize the sexual process (Figure 2). A bioassay based on zygophore counts with minus Mucor mucedo will detect about $0.01 \mu \mathrm{g}$ of trisporic acid $\mathrm{C}^{52.61}$. What is the mechanism of this morphogenic action?

The most obvious biochemical effect of trisporic acids is to increase isoprenoid bisynthesis ; they were first characterized ${ }^{62}$ following the discovery that they were responsible for very large increases in carotene production in mixed cultures of various Mucorales, including B. trispora ${ }^{63}$. The observation that this increase was paralleled by an increase in sterol production, and that both effects were blocked by protein synthesis inhibitors such as cycloheximide, led to the conclusion that trisporic acids derepress the synthesis of one or more of the early enzymes in the isoprene pathway ${ }^{64}$. We recently confirmed that the 'mating effect' in B. trispora also increases the synthesis of ubiquinones and prenols (Table 4 ) as this theory requires ${ }^{65}$. However, the four branches of the isoprenoid pathway are very unequally affected, as these results show, and this reminds us that there are other limiting controls. Certainly our own experience is that the increase in carotenoids is more affected by environmental factors than the increase in steroids, and indeed on media optimised for trisporic acid production the carotene response of B. trispora may be quite small. Similar factors must be at work in other Mucorales that do not produce such an excess of the hormones; some appear not to accumulate carotenes at all, and we presume they merely make sufficient to furnish the small amounts of trisporic acids actually needed for the mating process. The conclusion that the morphogenic hormones are degradation products of $\beta$-carotene, and that their action may frequently, but not necessarily, include an increase in carotenoid synthesis, goes far to explain the difficulties mycologists have hitherto found in correlating sexual differentiation with carotene accumulation ${ }^{66}$.

It is important to note that carotenes may also accumulate differentially in the homothallic Mucorales, in which one genotype can give rise to both plus and minus structures. Biochemically these homothallic species are little understood, and to some extent their carotene production can be compared with that in other organisms to which the trisporic acid system is presumably irrelevant, for example the accumulation of $\gamma$-carotene in differentiated chytrid fungi ${ }^{67}$ or in the gametes of some green algae ${ }^{35}$. In general terms,

Table 4. Isoprenoid levels in B. trispora

\begin{tabular}{lcccc}
\hline \multicolumn{1}{c}{ Strain } & \multicolumn{4}{c}{$\mathrm{mg} / \mathrm{g}$ fresh weight } \\
& Ergosterol* & $\beta$-Carotene & UQ & Prenols \\
\hline plus & 3.5 & 0.17 & 0.09 & 0.06 \\
minus & 9.2 & 0.8 & 0.26 & 0.10 \\
mated & 51.0 & $11 \cdot 0 \dagger$ & 0.52 & 0.35 \\
Average increase & $\times 8$ & $\times 22(\times 50)$ & $\times 3$ & $\times 4$ \\
\hline
\end{tabular}

- and 22-dihydro ergosterol

+ also $20 \mathrm{mg}$ trisporic acids $\equiv 35 \mathrm{mg}$ P-carotene 
such biochemical manifestations of a differentiation process are best explained in terms of induced enzyme processes which are triggered through environmental changes, the impact of which is relayed and amplified through the interlocking of primary metabolic sequences. The heterothallic Mucorales seem to have evolved a means of doing this which also necessitates contributions by two separate colonies and so has the evolutionary advantage of imposing an out-breeding requirement upon reproductive differentiation, but the nature of the mechanism which in this group of organisms is partitioned between the strains may be a pointer to unsuspected complexities in single systems. For example in the homothallic Mucorales some species will substitute for a plus heterothallic in collaborating with a minus, and so we presume they have at least part of the same machinery; in the self-differentiation of these same homothallic species two types of zygophores are formed and carotene usually accumulated only in one. Similarly in Allomyces and other chytrids where sexual differentiation is phenotypic only the 'male' organs accumulate $\gamma$-carotene, and indeed caroteneless mutants produce only 'female' gametes ${ }^{66,68}$.

The only direct function which may be ascribed to carotenoids per se in these sexual processes is a role as monomeric precursors for the pigmented polymeric material which frequently forms a highly-resistant protective coating on sexual spores. Gooday has recently suggested ${ }^{69}$ that in Mucorales this is a type of 'sporopollenin', while in Blastocladiella the developmental pathway which leads to a thick-coated resistant spore is precisely the one in which $\gamma$-carotene synthesis is most marked ${ }^{67}$.

It is possible to conceive of direct uses for higher levels of ubiquinones and prenols in zygophore differentiation, simply because the outgrowth of the zygophores is a rather rapid development needing a local increase in metabolism-presumably linked to respiration in which ubiquinones function -and in wall-growth, which presumably utilizes prenol phosphates as monomer carriers. However, these seem rather small features through which to attempt an explanation of the morphogenetic effect, though doubtless they could be helpful, and Table 4 shows that the mating effect on these types of isoprenoid is minimal. In some respects the trisporate-mediated increase in sterols offers more attraction as part of a differentiation mechanism.

Fungal sterols are partly accumulated in 'secondary' lipids and partly functional, apparently in maintaining the osmotic functions of the cell membranes in which they are located. In those aquatic Phycomycetes which cannot make sterols, exogenous sterols are specifically required for the development of reproductive structures ${ }^{70}$. Even in other fungi which can make their own sterols, some parallel evidence is available from studies of the effects of steroid synthesis inhibitors, in particular of SKF 3301-A (2,2-diphenyl-1- $\beta$-dimethylaminoethoxy)-pentane hydrochloride), the action of which is mainly (though unfortunately not exclusively) at the squalene level of sterol synthesis. In a Cochliobolus (Sphaeriales) this inhibitor selectively blocks sexual differentiation and the effect is reversed by added sterols $^{71}$; similar but less clear-cut results have been obtained with Sordaria (also in Sphaeriales) ${ }^{72}$. The most striking example of a sterol functioning in sexual differentiation is of course in Achlya (Phycomyces, Saprolegniales), 
where as already mentioned a hormone system, functionally rather similar to the trisporic acid system, is based upon the specific sterol, antheridiol ${ }^{73}$, which inter alia acts as inducer for enzymes which alter the plasticity of the cell walls ${ }^{74}$. What may be a similar system in certain yeasts is much less securely established and awaits chemical investigation ${ }^{75,76}$, but in the Mucorales any steroid effects are clearly due to normal sterols and on a grosser scale. Using Mucor mucedo on surface cultures containing SKF 3301-A, we have recently found that at inhibitor levels greater than $0.5 \mathrm{~mm}$ there is a very marked and fairly specific effect upon the formation of zygophores in the contact zone between plus and minus colonies; the induction of zygophores in a single colony by added trisporic acid is strongly inhibited at concentrations of $1.0 \mathrm{~mm}$ or greater. Both effects are far more marked than the effect of the inhibitor on vegetative growth, as Figure 12 indicates. Less readily quantifiable but in some ways more marked is the effect of lower inhibitor levels, around $0.2 \mathrm{~mm}$, on the nature and behaviour of the zygophores; compared with controls they are more fragile and in plus-minus contacts they grow erratically - when oppositely-sexed zygophores meet they do not always differentiate in the normal way and they may continue to elongate, or branch out, or revert to vegetative hyphae. This behaviour certainly suggests that the enhancement of sterol synthesis provoked by trisporic acids is rather directly functional in the morphogenetic response.

However, there is another less direct way in which the derepression of isoprenoid synthesis by trisporic acids may be functional in differentiation. The data of Table 4 show that in mated cultures there can be a tenfold overall increase in metabolism by the isoprene pathway. This means a tenfold increase in the consumption of basic metabolic intermediates such as acetyl-CoA, ATP, and reduced coenzymes, with corresponding readjustments of major sections of general metabolism. As already noted, such changes are precisely of the kind which, when engendered by environmental changes, seem quite generally to trigger developmental responses, having

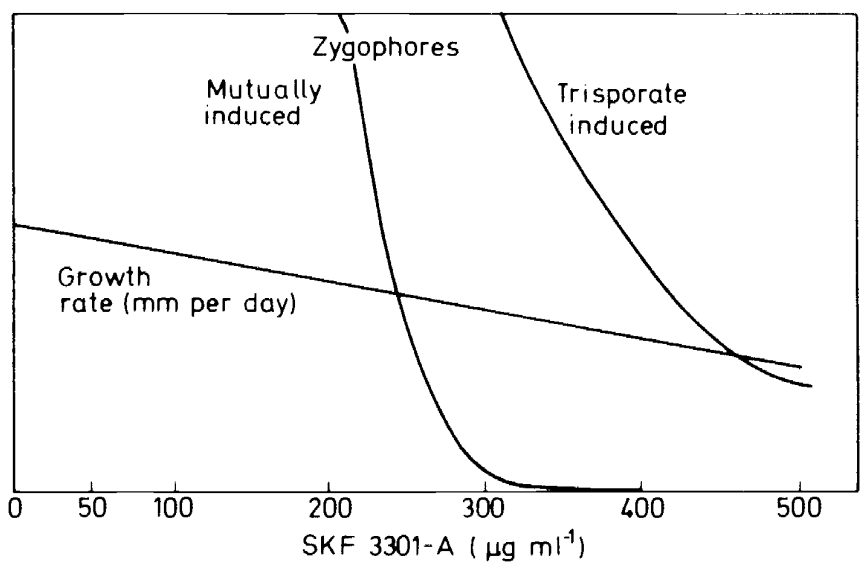

Figure 12. The effect of the sterol inhibitor SKF 3301-A on Mucor muceaio. 
their effects amplified by the derepression of some enzymes and the repression of others; this is the phenotypic equivalent of a pleiotropic mutation, and good examples in the field of gunal differentiation are the developmental processes in Blastocladiella as analysed by Cantino ${ }^{67}$, and the surprisingly similar view of sporulation in Aspergillus more recently developed by Smith $^{77}$. It is almost inevitable that effects of this kind should also be triggered by the trisporic acid effect, but a considerable volume of biochemical work would be needed to explore them adequately; to initiate a short cut we are currently testing cyclic AMP derivatives on $M$. mucedo. Cyclic AMP is of course number one in the 1972 hit parade; more seriously it is a likely mediator between changes in metabolic flows and certain types of derepressible enzymes. Preliminary results are that its morphogenic effects in $M$. mucedo are conspicuous but confusing; they appear to include what can only be described as clumsy efforts towards zygophore formation. Presuming that much of the clumsiness is in our own hands the work will continue!

\section{CONCLUSIONS}

For the present, our account of the isoprenoid pathway has come full circle and we have returned to the species with which our review began. From the standpoint of traditional chemotaxonomy it has been less than adequate, for the growing range of variety of truly secondary metabolites which are known to be formed by this pathway in fungi offers promising material for initial classificatory studies. Instead I have tried to illustrate some of the less obvious levels of natural product studies at which comparative exercises are, or will be, equally fruitful; the objective, a truer comprehension of the structured variety of living systems, remains the same.

\section{REFERENCES}

1 W. B. Turner, Fungal Metabolites London (1971).

${ }^{2}$ L. J. Goad, in T. W. Goodwin (ed.), Natural Substances Formed Biologically From Mevalonic Acid (Biochem. Soc. Symp. 29, 45 London (1970).

3 L. J. Goad and T. W. Goodwin, Progr. Phytochem. 3 in press (1972).

${ }^{4}$ C. Anding. R. D. Brandt, G. Ourisson, R. J. Pryce and M. Rohmer, Proc. Roy. Soc. B 180, 115 (1972).

${ }^{5}$ G. J. Schroepfer, B. N. Lutsky, J. A. Martin, S. Hurtoon, B. Fourcans, W. H. Lee and J. Vermilion. Proc. Roy. Soc. B. 180, 125 (1972).

${ }^{6}$ K. Bergman, P. V. Burke, E. Cerdà-Olmedo, C. N. David, M. Delbrück, K. W. Foster, E. W. Goodell, M. Heisenberg, G. Meissner, M. Zalokar, D. S. Dennison and W. Shropshire, Bact. Rev. 33, 100 (1969).

7 N. J. McCorkindale, S. A. Hutchinson, B. A. Pursey, W. T. Scott and R. Wheeler, Phytochem. 8, $861(1969)$.

${ }^{8}$ C. W. Bird, J. M. Lynch. S. J. Pirt and W. W. Reid, Tetrahedron Letters, 34, 3189 (1971).

${ }^{9}$ M. de Rosa, A. Gambacorta, L. Minale and J. D. Bu'Lock, Chem. Comm., 620 (1971).

10 D. Gelpi, H. Schneider, J. Mann and J. Oro, Phytochem. 10, 603 (1971).

11 L. J. Mulheirn and E. Caspi, J. Biol. Chem. 246, 2494 (1971).

12 A. Kawaguchi and S. Okuda, Chem. Comm. 1012 (1970).

13 G. Goulston and E. I. Mercer, Phytochem. 8, 1945 (1969).

14 D. H. R. Barton, V. M. Kempe and D. A. Widdowson, J. Chem. Soc. 513 (1972).

15 K. Alexander, M. Akhtar, R. B. Boar, J. F. McGhie and D. H. R. Barton, Chem. Comm. 383 (1972);

(a) P. J. Doyle, G. W. Patterson, S. R. Dutky and M. J. Thompson, Phytochem. 11, 1951 (1972). 
16 W. R. Nes, Lipids, 6, 219 (1971).

17 M. C. Ritter and M. E. Dempsey, J. Biol. Chem. 246, 1536 (1971).

18 J. W. Hendrix, Ann. Rev. Phytopath. 8, 111 (1970).

19 G. P. Arsenault, K. Biemann, A. W. Barksdale and T. C. McMorris, J. Amer. Chem. Soc. 90, $5635(1968)$.

20 A. W. Barksdale, Science 166, 831 (1969).

21 E. Merdinger and E. M. Devine, J. Bact. 89, 1488 (1965).

22 H-K. Lin, R. J. Langenbach and K. W. Knoche, Phytochem. 11, 2319 (1972).

23 D. R. Threlfall and G. R. Whistance, in T. W. Goodwin (ed.) Aspects of Terpenoid Chemistry and Biochemistry, p. 357. London (1971).

24 J. D. Bu'Lock, B. Kave and A. T. Hudson. Phytochem. 10, 1037 (1971).

25 A. Law, D. R. Threlfall and G. R. Whistance, Biochem. J. 123, 331 (1971).

26 J. D. Bu Lock and A. U. Osagie. J. Gen. Microbiol., in press (1973).

27 W. Steglich, F. Esser and I. Pils, Z. Naturforsch. 26b, 336 (1971).

28 P. C. Beaumont and R. L. Edwards. J. Chem. Soc. C. 2398 (1969).

29 L. Canonica, W. Kroszczynski, B. M. Ranzi, B. Rindone and C. Scolastico, Chem. Comm., 257 (1971).

${ }^{30}$ F. W. Hemming, in T. W. Goodwin (ed.) Natural Substances formed Biologically from Meralonic Acid, p. 105. London (1970).

31 R. M. Barr and F. W. Hemming, Biochem. J. 126, 1203 (1972).

${ }^{32}$ K. J. I. Thorne and E. Kodicek, Biochem. J. 99, 123 (1966).

${ }^{33}$ P. H. Dunphy, J. D. Kerr, J. F. Pennock. K. J. Whittle and J. Feeney, Biochem. Biophys. Acta 136, 136 (1967).

34 E. F. Durr and M. Z. Habbal, Biochem. J. 127, 345 (1972).

35 T. W. Goodwin, in (ed.) Aspects of Terpenoid Chemistry and Biochemistry p. 315. London (1971).

${ }^{36}$ G. Britton, in T. W. Goodwin (ed.) Aspects of Terpenoid Chemistry and Biochemistry p. 255. London (1971).

${ }^{37}$ S. Liaaen-Jensen, in T. W. Goodwin (ed.) Aspects of Terpenoid Chemistry and Biochemistry p. 223. London (1971).

38 T. W. Goodwin, Pure and Appl. Chem. 20, 483 (1969).

39 J. W. Porter, Pure and Appl. Chem. 20, 449 (1969).

40 R. E. Sabden and G. Turian, Mol. Gen. Genet. 108, 358 (1970).

41 M. D. de la Guardia, C. M. G. Aragón, F. J. Murillo and E. Cerdà-Olmedo, Proc Nat. Acad. Sci. 68, 2012 (1971).

42 A. Karunakaran. M. E. Karunakaran and F. W. Quackenbush, Arch. Biochem. Biophys. 114. $326(1966)$.

43 B. H. Davies, in T. W. Goodwin (ed.) Chemistry and Biochemistry of Plant Pigments p. 156. London (1965).

44 J. D. Bu'Lock. D. J. Austin, G. Snatzke and L. Hruben, Chem. Comm. 255 (1970).

${ }^{45}$ N. Arpin, J. L. Fiasson, M. P. Bouchez-Dangye-Caye, G. W. Francis and S. Liaaen-Jensen. Phytochem. 10, 1595 (1971).

46 S. Liaaen-Jensen. Phytochem. 4. 925 (1965).

47 R. Bonaly and J. P. Malenge, Biochem. Biophys. Acta 164, 306 (1968).

${ }^{48}$ M. J. Vacheron, G. Michel, R. Guillay and N. Arpin, Phytochem. 8, 897 (1969).

${ }^{44}$ M. Bae, T. H. Lee, H. Yokoyama, H. G. Boettger and C. O. Chichester, Phytochem. 10, 625 (1971).

${ }^{50}$ F. T. Haxo, Fortschr. Chem. Org. Naturstoffe 12, 169 (1955).

51 D. J. Austin, J. D. Bu'Lock and D. Drake, Experientia 26, 348 (1970).

52 J. D. Bu'Lock. D. Drake and D. J. Winstanley, Phytochem. 11, 2011 (1972)

53 J. D. Bu'Lock, S. Quarrie, D. Taylor and N. Winskill, J. Gen. Microbiol., in press (1973).

${ }^{54}$ G. Meissner and M. Delbrück, Plant Physiol. 43, 1279 (1968).

$55 \mathrm{M}$. Heisenberg and E. Cerdà-Olmedo, Mol. Gen. Genet. 102, 187 (1968).

56 R. P. Sutter. personal communication and at International Congress of Mycology (Exeter, 1971).

57 J. D. Bu'Lock and D. J. Winstanley, J. Gen. Microbiol. 69, 391 (1971).

58 J. D. Bu'Lock and D. J. Winstanley, J. Gen. Microbiol 68, xvi (1971).

59 H. van den Ende and D. Stegwee, Bot. Rev. 37, 22 (1971).

6, H. van den Ende, personal communication and at International Congress of Mycology (Exeter, 1971). 


\section{ISOPRENE PATHWAY. IN FUNGI}

61 G. W. Gooday, New Phytol. 67, 815 (1968).

62 L. Caglioti, G. Cainelli, B. Camerino, R. Mondelli, A. Prieto, A. Quilico, T. Salvatori and A. Selva, Tetrahedron. Suppl. 7, 175 (1966).

63 A. Ceigler, Ad1. Appl. Microbiol. 7, 1 (1965).

64 D. M. Thomas, R. C. Harris, J. T. O. Kirk and T. W. Goodwin, Phytochem. 6, 361 (1967).

65 J. D. Bu'Lock and A. U. Osagie, unpublished.

66 J. H. Burnett, in T. W. Goodwin (ed.) Chemistry and Biochemistry of Plant Pigments, p. 381. London (1965).

67 E. C. Cantino, XI Symp. Soc. Gen. Microbiol., 243 (1961).

68 J. M. Foley, Am. J. Bot., 45, 639 (1958).

${ }^{69}$ G. W. Gooday, P. Fawcett, D. Green and G. Shaw, J. Gen. Microbiol. 74, in press (1973).

70 J. W. Hendrix, Ann. Rev. Phytopath., 8, 111 (1970).

71 R. R. Nelson, D. Huisingh and R. K. Webster, Phytopathol. 57, 1081 (1967).

72 C. G. Flliot, J. Gen. Microbiol. 56, 331 (1969).

73 A. W. Barksdale, Science, 166, 831 (1969).

74 D. S. Thomas and J. T. Mullins, Science, 156, 84 (1967).

75 D. E. Hunt and P. L. Carpenter, J. Bact. 86, 845 (1963).

76 N. Yanagishima. Planta 87, $110(1969)$

77 J. E. Smith and J. C. Galbraith, Canad. J. Microbiol. 15, 1207 (1969). 